\title{
Malignant Nodular Hidradenocarcinoma Arising on the Areola of a Male Patient: Case Report of an "Orphan Disease" and Review of the Literature
}

Eleonora Giorgini ${ }^{1 *}$, Gregorio Tugnoli ${ }^{1}$, Silvia Aprile ${ }^{1}$, Guido Collina², Silvia Villani ${ }^{1}$, Andrea Biscardi ${ }^{1}$, Simone Maggioli $^{1}$, Eli Avisar ${ }^{3}$ and Salomone Di Saverio ${ }^{1}$

${ }^{1}$ Department of Emergency \& Surgery, Maggiore Hospital, Bologna Local Health District Largo Nigrisoli 2, 40100 Bologna, Emergency Surgery and Trauma Surgery Unit, Italy

${ }^{2}$ Department of Pathology, Maggiore Hospital, Bologna Local Health District Largo Nigrisoli 2, 40100 Bologna, Italy

${ }^{3}$ Department of Surgery, Sylvester Comprehensive Cancer Center, Miller School of Medicine, University of Miami, UM/SCCC 1475 NW 12 th Avenue, Rm, 3550, Miami, FL ZIP 33136, USA

\begin{abstract}
Herein we describe a rare case of an "orphan" neoplasm arising on an unusual site.

During the clinical examination, a mass of $3 \mathrm{~cm}$ was found on the left areola of a male patient. It was a solid, sliding on the deep layer, with a bluish color mass; therefore an excisional biopsy was performed. The histopathological diagnosis was nodular malignant hidradenoma. An oncological consulting recommended a surgical radicalization through a radical mastectomy. No adjuvant therapy has been given. The patient is alive with no evidence of disease after one-year follow up.
\end{abstract}

Keywords: Male breast cancer; Eccrine gland-derived carcinoma; Malignant hidradenoma; Surgical oncology

\section{Introduction}

The malignant eccrine glands neoplasms are rare tumors and therefore their low incidence makes difficult to collect in only one centre the sufficient number of cases to know their biological behavior and to have enough experience for assessing the best treatment and prognosis.

Malignant, potentially malignant and benign skin appendageal tumors, which are commonly defined as rare, are quite numerous instead [1]. The recognition is very important because eccrine carcinomas have potential local destruction and metastasis.

\section{Case Report}

An 82-year-old man was admitted to A\&E complaining of abdominal pain with nausea and vomiting. During physical examination, a $3 \mathrm{~cm}$, irregular, roundish, bluish lesion was found on his left areola in proximity of the nipple. This lesion had arisen 3 months before our visit. A biopsy was performed. In consideration of the clinical aggressive behavior of the found tumor $(\mathrm{MNH})$ a radical mastectomy was performed. In this latter surgical specimen residual foci of neoplastic cells were found, but margins were free of tumor. A clinical follow up every 6 months has been considered to be the appropriate approach, without an adjuvant therapy, because of the surgical radicalization and the age of the patient.

\section{Histopathology}

Histopathology showed that the tumor was composed of variable dimension nodules, papillary structures and hemorrhagic areas. Margins were irregular but pushing and no connection with the epidermis was seen (Figure 1). Cells composing the nodules and the papillary structures were round with round nucleus and a small centrally placed nucleolus and scanty cytoplasm. Cells with clear cell changes and focal glandular formations were evident. Comedonecrosis was also focally present (Figure 2). Mitoses were more than occasional, some of them atypical. Stroma had a pale homogeneous character, highly vascularized. Blood vessels infiltration by neoplastic cells was also present. A diagnosis of malignant nodular hidradenocarcinoma (MNH) was made.

\section{Immunohistochemistry}

Immunohistochemitry revealed strong positivity for Epithelial Membrane Antigen (EMA), Estrogen and Progesterone Receptors (EPR) and CEA. P63, CFDP-15 and C-erbB2 were negative. Ki67 decorated $40 \%$ of neoplastic cells.

\section{Discussion}

Eccrine neoplasms (poromas) were first described in 1956 [2]. Body involvement is: $65 \%$ on the soles, $10 \%$ on the palms and $25 \%$ in other regions (extremities, face, neck and trunk) [3]. Usually they are solitary lesions but a multiple lesions form has been reported and classified as "poromatosis". These lesions occur in clusters and tend to be normally pigmented [3], but may also appear hyperpigmented for the excessive presence of melanin, or purplish for proliferation of blood vessels [4]. The diameter usually varies from 0.2 to $1.5 \mathrm{~cm}$ but in our case it was $3 \mathrm{~cm}$. The peak of incidence is in the sixth decade of life [3].

\section{Histologic considerations}

Although sweat-glands neoplasms generally arise from the eccrine cellular lineage, they exhibit cellular growth patterns that may further influence the neoplasm's architecture. Hidradenoma may exhibits

*Corresponding author: Eleonora Giorgini, Department of Emergency \& Surgery Maggiore Hospital, Emergency Surgery and Trauma Surgery Unit, Bologna Local Health District Largo Nigrisoli 2, 40100 Bologna, Italy, Tel: 0039/3289286411; Fax Number: 0039-051-6478860; E-mail: elegio26@hotmail.it

\section{Received April 12, 2012; Accepted May 18, 2012; Published May 22, 2012}

Citation: Giorgini E, Tugnoli G, Aprile S, Collina G, Villani S, et al. (2012) Malignant Nodular Hidradenocarcinoma Arising on the Areola of a Male Patient: Case Report of an "Orphan Disease" and Review of the Literature. J Carcinogene Mutagene 3:129. doi:10.4172/2157-2518.1000129

Copyright: ( 2012 Giorgini E, et al. This is an open-access article distributed unde the terms of the Creative Commons Attribution License, which permits unrestricted use, distribution, and reproduction in any medium, provided the original author and source are credited. 
both cystic and solid features and that is why it enters on differential diagnosis with apocrine tumors; in fact there are divergent opinions on the primitive cellular lineage [5,6]. The issue is complicated by the coexistence of eccrine and apocrine cells inside cutaneous hamartomas or inside adnexal tumors with mixed differentiation (follicular and sebaceous). Coexistence of both eccrine and apocrine components has been already proved within the same lesions as Syringocystadenoma Papilliferum (SCAP) and Fox-Fordyce disease [7]. Some authors believe that these glands are synonymous with cutaneous Mammary-Like Glands (MLG), which are now recognized to be a normal component of the skin in the anogenital region, including the perianal skin [8]. MLG have features of apocrine, eccrine and mammary glands. The past assumption that these glands represent ectopic/accessory breast tissue lying along the milk line (mammary ridge) is now believed to be incorrect. These lesions often have a papillary pattern that reminisces the fibrous stroma of fibroepithelial lesions of the breast. A helpful feature in attributing MLG origin to an adnexal tumor is the presence of normal MLG in the deep dermis and in subcutaneous fatty tissue, the vicinity of the lesions of interest, with a transitional zone between normal and lesional areas. However, it is important to mention at the outset of this review that many of the sweat gland tumors that were traditionally assumed to have an eccrine origin have been now recognized to have apocrine counterparts as well, and vice versa.

\section{Immunohistochemical and pathological considerations}

In the first studies [9], specimens were stained by hematoxylin and eosin, and by immunoperoxidase techniques for the presence of S-100 protein, CEA, keratin, actin, vimentin, EMA, and with the fluid protein-15 (GCDFP-15) of cystic disease. Two different histopathological patterns of mixed tumors became apparent, namely, the apocrine and eccrine pattern. Nowadays we know that the cell in the excretory coil expresses positivity for Low Molecular Weight Keratin (LMWK), EMA and CEA, as well as S100 in the basal layer. The acrosyringeal cells (intra-epidermal portion) are stained with the High Molecular Weight Keratin (HMWK) and Cytokeratin (CK) 14. The

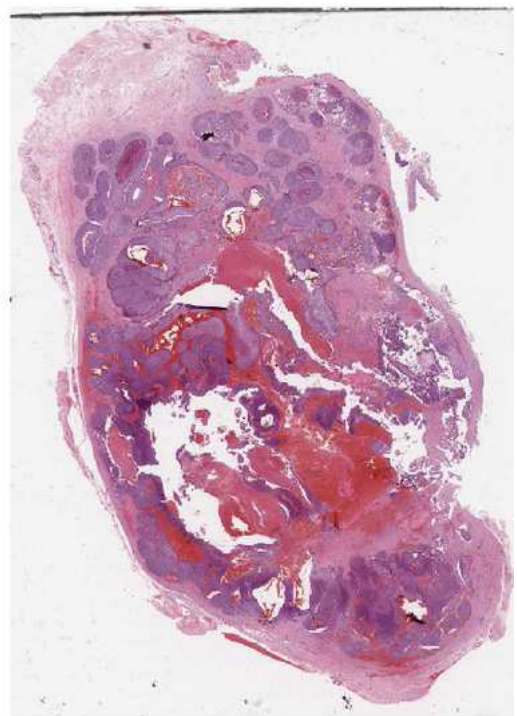

Figure 1: The neoplastic nodule was partially cystic with irregular margins.

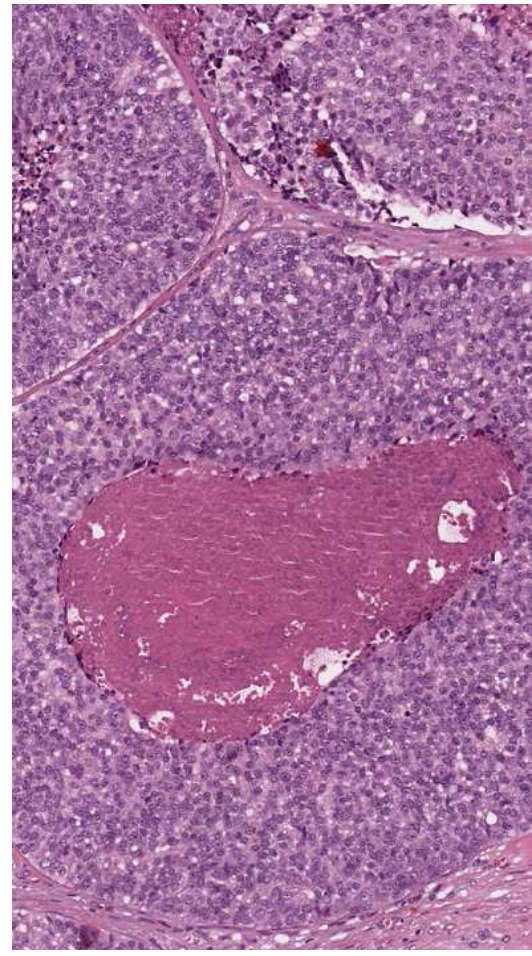

Figure 2: Comedonal necrosis in the centre of neoplastic nodule.

skin tumors with eccrine differentiation often also express positivity for EPR [10]. The positivity of some eccrine carcinomas to EPR has important clinical implications, as affected patients may be treated with hormonal therapy. Unfortunately, positivity for EPR does not distinguish cutaneous eccrine tumors from cutaneous metastases of breast carcinoma, in which case the clinical and radiological approach becomes fundamental.

The carcinoma is distinguished from benign hidradenoma for the presence of brisk mitotic activity and cellular pleomorphism.

Clear cell hidradenoma and hidradenocarcinoma may occasionally mimic metastatic clear cell carcinomas including the thyroid, the lung or renal cell carcinomas. However, the first two are usually distinguished by their positivity to Thyroid Transcription Factor-1 (TTF-1) and the latter by its prominent vascularity, and the presence of hemorrhage and focal granular necrosis within the lesion. The Renal cell carcinoma also expresses both EMA and CD10.

\section{Literature background}

MNH was first reported in 1954 [11]; until 2004, only 70 cases have been documented in the English literature, 17 of which were included in the series of Berg and McDivitt [12]. Our literature review has been performed by using PubMed as research instrument and selecting "malignant nodular hidradenoma" as key word. 135 items were found. Papers are not homogenous with each other. There are 21 case reports [1,13-32], 7 case reports with literature review [33-39], 4 case reports with histological considerations [40-43], 1 descriptive article [44] and 1 case report with histological and immunohistochemical considerations and indications of treatment [45]. The sum of the cases reviewed in these articles is 138 . The overall incidence of all eccrine carcinomas is $6 \%$ which represent $<1 \%(0.1-1)$ of all skin neoplasms The common 
provided information concerns the localization; only six cases had a chest localization $[21-25,39,42]$ but none concerning the areola.

The most recent cases $[39,42]$ have been treated with a wide local excision (no free margins declared) and subjected to adjuvant therapy. Both of them have developed local recurrence (14 months and 8 years respectively) and metastasis (regional lymph nodes and lung). Survival was 19 months in the first case and in the second it is not specified.

\section{Treatment and follow up}

MNH's pick of incidence occurs in sixth decade of life; with an equal male/female distribution; the tumor has a high local recurrence rate $(50 \%)$, metastases to lymph nodes, bones or visceral organs $(60 \%$ of cases) recurs within the first two years from diagnosis. Although this aggressive behavior is well-known, there is not a unanimous consensus about therapy and follow up. The general suggestion is to perform a wide abscission, but free margins are not established, as well as the utility and the rationale of adjuvant therapy.

A first primary treatment with a surgical excision with at least $2 \mathrm{~cm}$ free margins is suggested [39]. Some authors recommend a primary resection of 3-5 $\mathrm{cm}$ of safe margins. An inadequate excision of the primary lesion appears to be a poor prognostic factor because even lesions classified as benign have a propensity to recur locally if not fully excised. There is not an established consensus on lymph node dissection. The 5-year postsurgical survival rate for $\mathrm{MNH}$ is reported to be less than $30 \%$. As a consequence, therapeutic strategies should be appropriately planned for each case and however aggressive [46]. Mohs micrographic surgery may prove superior to the conventional excision and manifest a lower recurrence rate. At the time of excision of eccrine tumors, some researchers have utilized the Sentinel Lymph Node Biopsy (SLNB) to detect the possible regional microscopic lymph node metastasis. These authors suggest that spotting a sentinel lymph node could be the right diagnostic approach for staging the disease as it happens for breast cancer. Positivity of sentinel lymph node also permits to assess the indication for radical lymphadenectomy. Whether early detection and treatment of lymph node metastases could improve overall survival or not, however, is not clear at this time [47,48].

The choice of adjuvant therapy is controversial. Histopathology and immunohistochemistry of MNH may appear very similar to those of the ductal adenocarcinoma of the breast and of the salivary glands tumors. The EPR positivity has been reported in $21 \%$ of malignant eccrine tumors and in $33 \%$ of cutaneous metastases of ductal breast cancer. Busam and coworkers [10] compare the immunohistochemical staining of 42 primary sweat gland carcinomas with 30 breast metastasis of the skin and find no significant differences between the frequencies of EPR positivity. Antihormonal agents (AhA) have been documented in the management of eccrine carcinomas but their use is not currently considered the standard of care although a recent report described a case of metastatic sweat glands carcinoma treated with AhA resulting in a long time disease-free status $[46,49]$. We suggest to always checking EPR because patients with positive tests may also undergo an AhA therapy, remembering that the gain on survival is only evidence-based. Also the impact of chemo-radio therapy is still object of discussion, because an advantage in the overall survival has not been demonstrated yet. The rationale for adjuvant therapy can only be inferred by the literature: dimensions of the neoplasm (a tumor $\geq$ 4 is considered a big lesion), severity of histological picture, lymph nodes invasion or metastasis at the moment of diagnosis. Of course the age of the patient and his general condition influences the decision of adjuvant therapy. In the series of Souvatzidis [39], only two patients $(2 / 7)$ were not admitted to adjuvant therapy, all patients are dead for hemorrhage and/or local vascular invasion after a mean survival of 25.6 month and only the patient number 7 that was not treated with chemo/ radio therapy and was alive after 52 month from the operation.

We suggest a close follow up for the first 5 years, which is the period with the most elevate incidence of death and recurrence. There is no data about the practical utility of radiological staging; remembering that extensive metastasis to periesophageal, peribronchial, perioaortic and retroperitoneal lymph nodes, and via bloodstream to bones, vertebrae, ribs, pelvis, lung space, viscera and pleura have been reported $[11,23,34,50]$, a rational principle of cancer staging can be helpful.

\section{Conclusion}

This case allowed us to differentiate two rare tumors: male breast carcinoma, which accounts for less than $1 \%$ of all breast carcinomas and MNH. The peculiar histopathological features (neoplastic cells with eosinophilic, clear cytoplasm, focal glandular and papillary structures and hemorrhagic cystic spaces), along with negativity for GCFDP-15 led us to the diagnosis of $\mathrm{MNH}$.

Positivity for hormonal receptors is not helpful in the differential diagnosis because it is known that eccrine tumors can be positive to EPR.

In absence of a standardized diagnostic approach and a registered treatment, we suggest to always perform a wide abscission, and to perform a radical surgery on the basis of a histological diagnosis. The lymph node dissection is certainly indicated when there are signs of lymph node local invasion; prophylactic dissection otherwise has not yet proved to increase the free disease interval. The technique of SLNB can be a guideline to take decisions based on objective clinical elements. The aggressive behavior is the correct way to treat this disease which is as rare as aggressive and in our opinion it should be deeply investigated and treated with all resources until a consensus based on larger case series will be established.

\section{References}

1. Nair PS (2008) A clinicopathologic study of skin appendageal tumors. Indian J Dermatol Venereol Leprol 74: 550.

2. Goldman P, Pinkus H, Rogin JR (1956) Eccrine poroma; tumors exhibiting features of the epidermal sweat duct unit. AMA Arch Derm 74: 511-521.

3. Ackerman AB, Abenoza P (1990) Neoplasms with eccrine differentiation Philadelphia (PA) Lea \& Febiger: 113-85.

4. Moore TO, Orman HL, Orman SK, Helm KF (2001) Poromas of the head and neck. J Am Acad Dermatol 44: 48-52.

5. Groben PA, Hitchcock MG, Leshin B, White WL (1999) Apocrine poroma: distinctive case in a patient with nevoid basal cell carcinoma syndrome. Am J Dermatopathol 21: 31-33

6. Harvell JD, Kerschmann RL, LeBoit PE (1996) Eccrine or apocrine poroma? Six poromas with divergent adnexal differentiation. Am J Dermatopathol 18 $1-9$

7. Kamada A, Saga K, Jimbow K (2003) Apoeccrine sweat duct obstruction as a cause for Fox-Fordyce disease. J Am Acad Dermatol 48: 453-455.

8. van der Putte SC (1994) Mammary-like glands of the vulva and their disorders Int J Gynecol Pathol 13: 150-160.

9. Hassab-el-Naby HM, Tam S, White WL, Ackerman AB (1989) Mixed Tumors of the skin. A histological and immunohistochemical study. Am J Dermatopatho 11: 413-428. 
10. Busam KJ, Tan LK, Granter SR, Kohler S, Junkins-Hopkins J, et al. (1999) Epidermal growth factor, estrogen, and progesterone receptor expression in primary sweat gland carcinomas and primary and metastatic mammary carcinomas. Mod Pathol 12: 786-793.

11. Keasbey LE, Hadley GG (1954) Clearcell hidradenoma; report of three cases with wide spread metastases. Cancer 7: 934-952.

12. Berg JW, McDivitt RW (1967) Pathlogy of sweat gland carcinomas. In: Pathology Annual London UK Sommers SL Vol 3.

13. Engel A, Bar-Dayan Y, Engelberg S, Levi $Y$ (1999) Malignant nodular hidradenoma--sweat gland tumor. Harefuah 136: 683-6,755.

14. De Toma G, Plocco M, Nicolanti V, Cavallaro G, Amato D, et al. (2000) Malignant nodular hidradenoma. A clinical case. Minerva Chir 55: 185-187.

15. Singh A, Sharma S, Verma S, Khanna A (2007) Malignant nodular hidradenoma with angiolymphatic invasion: a case report. Indian J Pathol Microbiol 50: 548549

16. Toulemonde A, Croue A, Rodien P, Verret JL (2006) Malignant nodular hidradenoma and multiple nodular hidradenomas in a hypogonadic patient. Ann Dermatol Venereol 133: 1005-1008.

17. Verret DJ, Kabbani W, DeFatta RJ (2007) Nodular hidradenocarcinoma over the parotid gland: a pathologic presentation. Head Neck 29: 193-197.

18. Khalil HM, Yusuf H, Kaddour HS (2003) Malignant eccrine hidradenoma of neck causing acute heart failure. Auris Nasus Larynx 30: 307-310.

19. Holden B, Colome-Grimmer M, Savage C, Stierman K, Pou AM (2002) Malignant eccrine acrospiroma with metastasis to the parotid. Ear Nose Throat J 81: 352-355.

20. Görtler I, Köppl H, Stark GB, Horch RE (2001) Metastatic malignant acrospiroma of the hand. Eur J Surg Oncol 27: 431-435.

21. Yildirim S, Aköz T, Apaydin I, Ege GA, Gïderoglu K (2000) Malignant clear cell hidradenoma with giant metastasis to the axilla. Ann Plast Surg 45: 102.

22. Buise MP, Kramer WL, Kniestedt WJ (1999) A woman with an advanced malignant clear cell hidradenoma. Ned Tijdschr Geneeskd 143: 1618-1621.

23. Long WP, Dupin C, Levine EA (1998) Recurrent malignant acrospiroma. Treatment by chest wall excision. Dermatol Surg 24: 908-912.

24. Waxtein L, Vega E, Cortes R, Hojyo T, Dominguez-Soto L (1998) Malignan nodular hidradenoma. Int J Dermatol 37: 225-228.

25. Cyrlak D, Barr RJ, Wile AG (1995) Malignant eccrine acrospiroma of the breast. Int J Dermatol 34: 271-273.

26. Kauderer C, Clarke HD, Fatone CT (1995) Malignant eccrine acrospiroma. A case study. J Am Podiatr Med Assoc 85: 116-117.

27. Stagnone GJ, Kucan JO, Gross K, Mann JL, Zook EG (1990)Malignant acrospiroma. J Hand Surg Am 15: 987-990.

28. Herraiz Serrano C, Santos Gil I, Calderón Montero A, Suárez Fernández C (1991) Malignant acrospiroma as a cause of fever of unknown origin. Med Clin 96: 316.

29. Hunt SJ, Santa Cruz DJ, Kerl H (1990) Giant eccrine acrospiroma. J Am Acad Dermatol 23: 663-668.

30. Carli P, Urso C, Vallecchi C (1990) Malignant acrospiroma with "zoster-like" clinical expression. G Ital Dermatol Venereol 125: 157-160.

31. Wilson KM, Jubert AV, Joseph JI (1989) Sweat gland carcinoma of the hand (malignant acrospiroma). J Hand Surg Am 14: 531-535.

32. Ogilvie JW (1982) Malignant eccrine acrospiroma. A case report. J Bone Join Surg Am 64: 780-782.

33. Orlandi RR, Sercarz JA, Doberneck SA, Calcaterra TC (1994) Malignant clear cell hidradenoma of the upper lip. Head Neck 16: 443-449.

34. Ohta M, Hiramoto M, Fujii M, Togo T (2004) Nodular hidradenocarcinoma on the scalp of a young woman: case report and review of the literature. Dermatol Surg 30: 1265-1268.

35. Headington JT, Niederhuber JE, Beals TF (1978) Malignant clear cell acrospiroma. Cancer 41: 641-647.

36. Ashley I, Smith-Reed M, Chernys A (1997) Sweat gland carcinoma. Case report and review of the literature. Dermatol Surg 23: 129-133.
37. Wu H, Elenitsas R (2001) Malignant nodular hidradenoma in a patient with neurofibromatosis type 1: a case report and review of the literature. Cutis 68 273-278.

38. Lim SC, Lee MJ, Lee MS, Kee KH, Suh CH (1998) Giant hidradenocarcinoma: a report of malignant transformation from nodular hidradenoma. Pathol Int 48 : 818-823.

39. Souvatzidis P, Sbano P, Mandato F, Fimiani M, Castelli A (2008) Malignan nodular hidradenoma of the skin: report of seven cases. J Eur Acad Dermato Venereol 22: 549-554.

40. Garcia-Bonafe MM, Campins MM, Redecilla PH (2009) Malignant nodula hidradenoma on the scalp: report of a case with fine needle aspiration cytology features and histologic correlation. Acta Cytol 53: 576-580.

41. Pozo L, Camacho F, Rios-Martin JJ, Diaz-Cano SJ (2000) Cell proliferation in skin tumors with ductal differentiation: patterns and diagnostic applications. $J$ Cutan Pathol 27: 292-297.

42. Nash JW, Barrett TL, Kies M, Ross MI, Sneige N, et al. (2007) Metastatic hidradenocarcinoma with demonstration of Her-2/neu gene amplification by fluorescence in situ hybridization: potential treatment implications. J Cutan Pathol 34: 49-54.

43. Poroshin KK, Vavilov AM, Otsep NM, Seredniakova NI (1986) Acrospiroma (clinico-morphological characteristics and histogenesis). Arkh Patol 48: 70-76.

44. Glumov Vla, Kir'ianov NA, Kolosenko EG, Riashchikov SN (1991) Difficulties in the diagnosis of malignant acrospiroma. Vopr Onkol 37: 495-497.

45. Tolland JP, Brenn T, Guldbakke KK, Schanbacher CF (2006) Mohs micrographic surgery, sentinel lymph node mapping, and estrogen receptor analysis for the treatment of malignant nodular hidradenoma. Dermatol Surg 32: 1294-1301.

46. Mirza I, Kloss R, Sieber SC (2002) Malignant eccrine spiradenoma. Arch Patho Lab Med 126: 591-594.

47. Bogner PN, Fullen DR, Lowe L, Paulino A, Biermann JS, et al. (2003) Lymphatic mapping and sentinel lymph node biopsy in the detection of early metastasis from sweat gland carcinoma. Cancer 97: 2285-2289.

48. Delgado R, Kraus D, Coit DG, Busam KJ (2003) Sentinel lymph node analysis in patients with sweat gland carcinoma. Cancer 97: 2279-2284

49. Schröder U, Dries V, Klussmann JP, Wittekindt C, Eckel HE (2004) Successful adjuvant tamoxifen therapy for estrogen receptor-positive metastasizing sweat gland adenocarcinoma: need for a clinical trial? Ann Otol Rhinol Laryngol 113 242-244.

50. Ko CJ, Cochran AJ, Eng W, Binder SW (2006) Hidradenocarcinoma: a histological and immunohistochemical study. J Cutan Pathol 33: 726-730. 